Eixo Temático: Processos de Ensino-Aprendizagem

\title{
ET-06-004 \\ O LÚDICO NO PROCESSO DE ENSINO/APRENDIZAGEM: JOGOS E DINÂMICA NO ENSINO DE CIÊNCIAS E BIOLOGIA
}

Juma Gomes da Silva ${ }^{1}$, Diele Gonçalves Santos ${ }^{1}$, Maria Tereza Nonato², Eltamara Souza da Conceição ${ }^{3}$

${ }^{1}$ Bolsista ID PIBID-UNEB/CAPES. Universidade do Estado da Bahia. DCET II - Campus de Alagoinhas. Rod. Alagoinhas-Salvador, BR 100, KM 03. Alagoainha-BA. CEP. 48040-210. Email:mel.haney@hotmail.com.br, dieliysantos@hotmail.com.

${ }^{2}$ Supervisora PIBID-UNEB/CAPES. Colégio Estadual Luis Navarro de Brito. Centro. Alagoinhas-BA.

${ }^{3}$ Coordenadora de Área do PIBID-UNEB/CAPES. Universidade do Estado da Bahia. DCET II Campus de Alagoinhas. Rod. Alagoinhas-Salvador, BR 100, KM 03. Alagoainha-BA. CEP 48040-210.

http://dx.doi.org/10.21472/congrebio2016.et-06-004

\section{RESUMO}

Os jogos e as dinâmicas de grupo, no processo de ensino e aprendizagem, tornam as aulas atraentes e prazerosas e, em muitos casos, favorece a compreensão do conteúdo estudado. Visando a implementar diversas ações voltadas para o ensino de ciências e biologia, os bolsistas do Projeto PIBID/Ciências Biológicas - Campus II - UNEB, buscaram proporcionar aos discentes do ensino fundamental do Colégio Estadual Luis Navarro de Brito, em AlagoinhasBA, atividades lúdicas. Com isso foi desenvolvido o jogo da "televisão do conhecimento" e a dinâmica denominada "colhendo conhecimento" acerca do conteúdo de Ciências "As Plantas", em duas turmas: uma de $7^{\circ}$ ano regular e uma do EJA $7^{\circ} / 8^{\circ}$ ano. Isso contribuiu para 0 desenvolvimento de uma consciência crítica e uma autonomia satisfatória por parte dos discentes, na exposição e discussão do conteúdo. Conclui-se pela experiência vivida, que é notória a importância da realização de atividades lúdicas como ferramenta na construção do conhecimento científico na educação básica.

Palavras-chave: Ludicidade; Ensino-aprendizagem; Atividade lúdica.

\section{INTRODUÇÃO}

Apesar do uso das atividades lúdicas não serem algo recente, muitos professores não utilizam desses recursos como ferramenta frequente para a construção do conhecimento científico. Muitas vezes, esse problema ocorre por desconhecimento desse recurso como algo indispensável e eficiente no processo de ensino e aprendizagem.

Rego (2000) afirma que o uso dos jogos permite "ambientes desafiadores, capazes de estimular o intelecto, proporcionando a conquista de estágios mais elevados do raciocínio”. Favorecendo assim o desenvolvimento do conhecimento lógico.

Na visão da escola de Vygotsky, segundo Mello (2004), o papel da educação escolar é criar novas necessidades, provocando nos discentes o surgimento dessas e de novos interesses. Planejando suas ações para que os mesmos tenham a oportunidade de experiências diversificadas, para que possam experimentar atividades cheias de significado às suas vidas. Assim, sensibilizando-se quanto ao conteúdo trabalhado e sendo atuantes e participativos, durante as aulas expositivas e práticas. 
A utilização de jogos e dinâmicas desenvolvidos no contexto escolar precisam estar vinculada com a temática conteudista proposta e planejada para o ano letivo. De modo que tais jogos não podem, nem devem estar fora de tais temáticas e devem funcionar como suprimentos para aprendizagem dos conteúdos estudados em aulas expositivas. Assim, é necessário estabelecer o vínculo entre jogos e conteúdo. Santos e Jesus (2010) indicam a função educativa do jogo como a de oportunizar a aprendizagem do indivíduo, seu saber, seu conhecimento e sua compreensão de mundo.

Friedman (1996) considera que:

Os jogos lúdicos permitem uma situação educativa cooperativa e interacional, ou seja, quando alguém está jogando está executando regras do jogo e ao mesmo tempo, desenvolvendo ações de cooperação e interação que estimulam a convivência em grupo.

Dessa forma o educador precisa proporcionar formas didáticas diferenciadas, como atividades lúdicas, para que os discentes sintam-se estimulados a pensar. Para que isso seja suficiente, a intervenção do professor deve acontecer no ocasião certa, instigando os alunos a uma reflexão, que estimule a estruturação do conhecimento (CHAGURI, 2006).

$\mathrm{O}$ presente trabalho tem a finalidade de descrever atividades lúdicas aplicadas em turmas de educandos do $7^{\circ}$ ano regular e EJA $7^{\circ}$ e $8^{\circ}$ no Colégio Estadual Luiz Navarro De Brito, na cidade de Alagoinhas-Ba. Para isso, os bolsistas ID do Projeto PIBID desenvolveram a televisão do conhecimento e a dinâmica colhendo conhecimento para tornar a aula sobre "As plantas" atraente e estimulante.

\section{METODOLOGIA}

A professora supervisora iniciou a III unidade abordando o conteúdo "As plantas", enfatizado a evolução, a classificação, morfologia, fisiologia e importância das mesmas para a sociedade, a partir daí os bolsistas ID analisaram as dúvidas dos educandos, que surgiram no desenvolvimento da aula e planejaram uma aula lúdica, para execução de uma aula complementar mais dinâmica.

O jogo "televisão do conhecimento" consistiu na confecção de uma televisão, feita a partir de uma caixa de papelão customizada. Além disso, também foi utilizado um bastão de madeira (cabo de vassoura) e esse foi usado para mudar os tópicos do assunto, onde ao rodá-lo para cima ou para baixo, mudavam-se as imagens da televisão, feitas em papel metro. Esta usada primeiramente durante a aula complementar.

Seguiu-se com a dinâmica "colhendo conhecimento", que consistiu da preparação de uma macieira, produzida a partir de material em E.V.A., contendo perguntas sobre o que havia sido discutido anteriormente com a exposição da televisão do conhecimento. De forma que a sala, dividida em equipes, elegia um integrante de cada grupo para tirar a maça da macieira. Esta continha uma pergunta que era discutida e respondida pelos grupos e, se o grupo errasse a pergunta, os seus adversários poderiam respondê-la em seguida. A equipe que respondesse corretamente o maior número de perguntas vencia o jogo e levava o prêmio, que consistia em uma caixa de bombom.

\section{RESULTADOS E DISCUSSÃO}

O formato da televisão despertou a atenção dos educandos, despertando o interesse pelo conteúdo contido nesta. Durante a exposição do conteúdo, observou-se que os educandos mostraram autonomia para expor, de uma forma crítica, suas ideias e experiências acerca do assunto. 
No desenrolar da dinâmica com a macieira, a turma também demonstrou bastante interesse e euforia. Tendo os pibidianos até que intervir para a realização da mesma fosse tranquila, pois precisariam de calma para analisar as perguntas e respondê-las lucidamente.

Uma aula lúdica nos proporciona vivenciar experiências significativas no que diz as práticas docentes, no desenvolvimento de metodologias dinâmicas, aplicadas em sala de aula. Com o desenvolvimento destas propostas verificou-se que a ciência necessita ser trabalhada, de uma forma que envolva o educando e perceba sua realidade e suas necessidades. Como citam Rizzi e Haydt (1994), através do lúdico, os alunos aprendem, aliando a necessidade de brincar, com o desejo de conhecer e isso facilita a compreensão de vários conceitos.

Com a execução do jogo foi perceptível como uma atividade diferente da costumeira chama a atenção dos discentes, gerando em primeira instância euforia, que dá lugar à criação. Permitindo tornarem-se construtores do saber, desenvolvendo neles capacidade crítica. O ensino de Ciências é citada nos Parâmetros Curriculares Nacionais (1998), onde se considera que seja imprescindível, no processo de ensino aprendizagem, o incentivo de atitudes de curiosidade, de respeito à diversidade de opiniões, à persistência na busca e compreensão das informações obtidas, de valorização da vida, da preservação do ambiente, de apreço e respeito à individualidade e a coletividade. Então, atividades como estas podem contribuir, neste sentido, para alcançar esses objetivos.

Durante a exposição do conteúdo, por meio da televisão do conhecimento, os discentes expuseram suas dúvidas, por meio de perguntas bem elaboradas, bem como emitiram críticas. Foi possível trabalhar o conteúdo "As plantas" sob diversos aspectos, tais como Sistemática Filogenética, morfologia, fisiologia e os benefícios sociais e econômicos das plantas. A temática abordada foi, o tempo todo, relacionada com o cotidiano da turma, de forma que os mesmos apresentaram sua vivência em relação ao objeto de estudo. De acordo com as diretrizes curriculares de Ciências para o Ensino Fundamental, o lúdico deve ser considerado, nas estratégias de ensino, independente da série e da faixa etária do estudante. Ajustando os encaminhamento de recursos utilizados como apoio. Sendo a ludicidade também relevante para o ensino e a aprendizagem, porque além de motivação os alunos, também o faz com os professores.

O lúdico, segundo Chaguri (2006), é caracterizado pelo prazer e esforço espontâneo. Tornando o aprender prazeroso. Devido a sua capacidade de absorver o indivíduo de forma intensa, além de criar um clima de entusiasmo. Este envolvimento emocional é que permite ao lúdico, ser uma atividade motivadora, geradora de um estado de euforia.

Cabe ressaltar que, para os jogos alcançarem seu real potencial didático como recurso na sala de aula da Educação Básica, é necessário que haja planejamento e contextualização, através do projeto pedagógico (PEDROSO, 2009). Assim o jogo não deve estar dissociado do conteúdo programático, garantindo assim a contextualização e a real aplicação dos fundamentos do uso desse recurso no processo de ensino e aprendizagem, promovendo o desenvolvimento intelectual dos discentes. O lúdico deve fazer parte do processo de ensinar, pois propicia ao aluno construir uma aprendizagem consciente e espontânea (RIZZI e HAYDT, 1998).

Na dinâmica "colhendo conhecimento" pode-se constatar que a aprendizagem sobre o conteúdo abordado no jogo foi alcançada, pois quando respondiam às perguntas contidas na macieira, era perceptível a sua apropriação.

Assim, o desenvolvimento destas atividades lúdicas foram um sucesso, tanto para a turma da $7^{\circ}$ ano regular quanto no EJA $7^{\circ} / 8^{\circ}$ ano. Ambas demonstraram empatia pelo trabalho proposto e o aprendizado foi muito significativo.

Santos (1999) afirma que:

Um novo paradigma é uma nova escala de valores, é uma nova cosmovisão que, por ser nova, é captada por poucos que, por serem mais criativos, são também mais corajosos e capazes de incentivar a busca por novos caminhos que possam levar à transformação. (SANTOS, 1999) 
Por isso é preciso ultrapassar os obstáculos e implementar atividades nas escolas, diferentes daquelas corriqueiras, onde métodos tradicionais dão lugar a possíveis formas mais prazerosas de aprender.

\section{CONCLUSÕES}

A utilização dos recursos lúdicos propostos e apresentados aqui, o processo de ensino e aprendizagem, foi eficaz, como ferramenta motivacional, colaborando para o desenvolvimento intelectual dos educandos. Sendo benéfico para a ampliação daquilo que se aprendeu na aula expositiva.

Pôde-se constatar ainda que o êxito de qualquer atividade de ensino deve ser bem planejada pelo docente, para que seja motivadora e rica, despertando a criatividade dos educando, fazendo com que sejam instigados a pensar, a criticar, argumentar e formular questionamentos a respeito da temática trabalhada. Oportunizando experiências diversificadas de atividades cheias de significado.

\section{AGRADECIMENTOS}

Agradecemos ao PIBID/CAPES - UNEB pela concessão das bolsas de Iniciação à Docência, de Coordenação de Área e de Supervisão, que tem nos possibilitado inúmeras novas experiências, na rotina dinâmica dos espaços escolares.

\section{REFERÊNCIAS}

BRASIL. Secretaria de Educação Fundamental. Parâmetros curriculares nacionais: Ciências. Brasília: MEC/SEF, 1998.

CHAGURI, J. P. O uso de atividades lúdicas no processo de ensino/aprendizagem de espanhol como língua estrangeira para aprendizes brasileiros. 2006. Disponível em: <http://www.unicamp.br/iel/site/alunos/publicações/textos/u00004.htm>. Acesso em: 1 abr. 2016.

FRIEDMANN, A. Brincar, crescer e aprender: o resgate do jogo infantil. São Paulo: Moderna, 1996.

MELLO, S. Al. A Escola de Vygotsky. In: CARRARA, K. (Org.). Introdução à Psicologia da Educação. São Paulo: Avercamp, 2004.

PEDROSO, C. V. Jogos didáticos no ensino de biologia: uma proposta metodológica baseada em módulo didático. In: CONGRESSO NACIONAL DE EDUCAÇÃO - EDUCERE, 9, ENCONTRO SUL DE PSICOPEDAGOGIA, 3, 2009. Curitiba, PUC/PR. Anais..., 2009.

REGO, T. C. Vygotsky: uma perspectiva histórico-cultural da educação. 10 ed. Petrópolis: Vozes, 2000.

RIZZI, L.; HAYDT, R. C. Atividades lúdicas na educação da criança. São Paulo: Ática, 1994.

RIZZI, L.; HAYDT, R. C. Atividades lúdicas na educação da criança. São Paulo: Ática, 1998.

SANTOS, E. A. C.; JESUS, B. C. O lúdico no processo ensino aprendizagem. Assunción, Paraguay: Universidad Tecnológica Intercontinental, 2010. (Dissertacion). 
SANTOS, S. M. P. (Org.). O lúdico na formação do Educador. 3 ed. Petrópolis: Vozes, 1999.

SILVEIRA, A. F.; ATAÍDE, A. R. P.; FREIRE, M. L. F. Atividades lúdicas no ensino de Ciências: uma adaptação metodológica através do teatro para comunicar ciências a todos. Educar, n. 34, p. 251-262, 2009. 